\title{
Can Perfume Increase The Response Rate To A Face-To-Face Survey?
}

Larisa Adenskaya, California State University, Northridge

Curt J. Dommeyer (E-mail: curt.dommeyer@csun.edu), California State University, Northridge

\begin{abstract}
After this paper reviews the literature related to the use of scent in marketing and other fields, it describes an experiment that manipulated the use of a perfume on a personal interviewer. The results indicate that perfume can be used to enhance the response rate to a face-to-face survey without incurring a sample bias or affecting the item omission rate. Suggestions for future researchers are offered.
\end{abstract}

\section{Introduction}

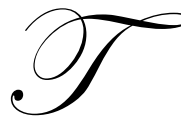

here has been a considerable amount of work devoted to determining the factors that affect response to face-to-face interviews. Much of the research has focused on the effects of interviewer demographic variables (e.g., gender, age, social class, religion, education, and race), interviewer skills, experience, and attitudes, and social distance between the interviewers and interviewees (Benney et al. 1956; Collins 1980; Colomotos et al. 1968; Freeman and Butler 1976; Huddy et al. 1997; Webster 1996). Some of the more recent studies have investigated how monetary and nonmonetary incentives affect response to face-to-face surveys (Goyder 1994; Lynn 2001; Singer, et al.1999; Willimack et al.1995). Other research has examined whether a face-to-face interview would benefit from the use of an advance letter (Lynn et al.1998) or a touch and gaze strategy (Shmuel and Hornick 1989). The present study attempts to extend the research on face-to-face interview strategies by examining the effects of a technique that has not been reported in the survey literature, namely the effects of using a pleasant fragrance on the interviewer.

The marketing literature offers numerous examples where scent has been introduced to either a product or shopping environment to stimulate sales. Neff (2000), for example, reports that vanilla scent has been added to fabric softener to trigger positive emotions from the consumer. Similarly, fragrance consultants have been hired by a variety of retailers to create a scent that, when sprayed into the store's atmosphere, will enhance the buying propensities of the consumer (Wilkie 1995). Ambient scent has been productively used by furniture and shoe stores (Reda 1994), stores that sell chocolate and bakery items (Hunter 1995), supermarkets (Bainbridge 1998), restaurants (Petran 1998) and gambling casinos (Chase 1998).

Despite the abundant anecdotal accounts supporting the use of scent in a marketing context, there has been limited scholarly research investigating the effects of scent applications in marketing. Knasko (1989), comparing the effects of scented and unscented store environments, found that consumers in the scented stores spent more time shopping but did not buy more merchandise. Similarly, Bone and Ellen (1994) found that subjects spent more time on a catalog-shopping task when rooms were scented. Hirsch (1995) found that gamblers spent more money on slot machines when the casinos were sprayed with a pleasant fragrance. Sprangenberg et al. (1996) manipulated the application of scent in a simulated store and found that product evaluations were generally more positive in the scented condition. They also found that subjects in the scented condition perceived that they had spent less time in the store than those in the unscented condition. They got these results despite the fact that none of the subjects mentioned the presence of a scent. And though the researchers experimented with several scents and several intensities, their results indicate that neither the type of scent nor the intensity of the scent had a dramatic effect on the results. Mattila and Wirtz (2001) experimented with three scent and three music conditions in a store environment and found that the main effect of the scent treatment was to increase "approach behavior" (as measured 
by an "approach-avoidance" scale containing eight items) and to increase the evaluation of the store's environment. Morrin and Ratneshwar (2000, 2003), in a laboratory setting, used a computer terminal to expose students to a variety of familiar and unfamiliar brands under scented or unscented conditions. In their 2000 study, they found that students in the scented condition were not only more likely to provide a positive evaluation of a brand, but they also were more likely to have recall of unfamiliar brands. Their 2003 research revealed that ambient scent increased recall and recognition of both familiar and unfamiliar brands. The researchers concluded in both investigations that benefits achieved from the ambient scent were due to the increased amount of time spent evaluating the brands during the scented conditions. Scent appears to have its impact on memory by inducing subjects to focus longer on stimuli.

\section{Conceptual Background}

It is not completely understood how scent induces consumers to act favorably toward pleasant smelling objects or environments. It has been suggested that several mechanisms may be working independently or jointly to create the desired effect (Morrin and Ratneshwar 2000, 2003). One mechanism is mood. It is possible that a pleasant scent improves a subject's mood, causing the subject to be more receptive to marketing stimuli. Although some studies have found that scent does affect mood (Baron 1990, 1997; Baron and Thomley 1994; Dunn et al. 1995; Lawless 1991), others have not (Morrin and Ratneshwar 2000, 2003).

A second mechanism is arousal. It is believed that scent can increase a person's physiological arousal level, thereby making the person more alert to deal with the task at hand. Some support for this notion has been found in the laboratory setting. Several researchers have found that scent affects subjects' brain wave and breathing patterns, suggesting altered arousal levels (Lorig and Schwartz 1988; Schwartz et al. 1986a, b; Takagi 1989). However, when self-reports of arousal have been obtained in brand experiments that manipulate scent, no support for the arousal mechanism has been found (Morrin and Ratneshwar 2000, 2003).

A third mechanism is attention. This mechanism can be understood by referring to an approach/avoidance model postulated by Mehrabian and Russell (1974). This model proposes that an individual's response to environmental stimuli is related to the nature of the stimuli: stimuli that have pleasant qualities will result in approach behavior (e.g., looking at, coming closer, or talking to an individual) while stimuli that have negative qualities will result in avoidance behavior (e.g., looking away and staying away from an individual). Thus, if a scent is deemed attractive to an individual, the individual should be inclined to exhibit approach behavior, resulting in more time spent near the scented object or environment. Several researchers who have conducted scent experiments have found that individuals remain longer in scented environments, thereby providing support for the attention mechanism (Bone and Ellen 1994; Knasko 1989; Morrin and Ratneshwar 2000, 2003).

\subsection{Scent And Helping Behavior}

When an individual consents to be interviewed, s/he is exhibiting a form of "helping behavior." While no studies have been reported that reveal how interviewer scent affects response to a personal interview, a few studies have been conducted that investigate whether scent affects an individual's willingness to help another person. Baron (1997) conducted two scent experiments in a shopping mall where passersby were asked to provide assistance (i.e., retrieve a dropped pen or make change for a dollar) to one or two individuals. The ambient scent of the experiment was manipulated by altering the location where requests were made. Helpful behavior was more likely to be exhibited by passersby when the request for their help was made in an area that had pleasant ambient odors (e.g., near a bakery or coffee house) than when the request was made in an area that did not have those odors. Baron and Thomley (1994) used a factorial design to determine the effect of two pleasant ambient fragrances and a prepaid nonmonetary incentive (i.e., candy) on students' moods and their willingness to volunteer their time for a future research project. Their results showed that mood of the students and their willingness to help the researcher were higher in the fragrance and gift conditions than they were in the control condition. They concluded that the fragrances and the prepaid gift elevated the moods of the subjects, thereby making them more willing to volunteer their time to a future project. In another study, Gueguen (2001) examined whether a woman's wearing of a heavy perfume would affect her ability to get help from pedestrians who noticed that she, apparently unknowingly, had 
dropped an item (either a packet of paper handkerchiefs or a glove). The results revealed that pedestrians were more likely to warn the woman that she had dropped an item when she was wearing perfume than when she was not.

\section{The Present Study}

Though it is not completely understood how and when scent will have positive effects on consumer behavior, it is apparent from the above research that scent, when properly applied, has the capacity to promote helpful behavior. In the present study, we attempt to determine whether perfume on a female interviewer will promote response to a personal interview. We believe that a pleasantly scented interviewer could increase the respondent's alertness and possibly elevate his/her mood. It could also enhance the attractiveness of the interviewer, thereby encouraging approach behavior. We, therefore, hypothesize that when a female interviewer wears a pleasantly smelling perfume, the response rate to the face-to-face survey will be higher than when perfume is not worn.

We are uncertain that the above hypothesis will be supported by the empirical data, for it rests on the assumption that the perfume will be perceived and appreciated by the survey candidate. Previous research on the relationship between perfume wearing and personal attraction is limited and has often produced results contrary to expectations. Baron (1981) conducted a 2 X 2 factorial design where he manipulated perfume wearing (on vs. off) and dress type (neat vs. informal) of females to determine if the manipulations would affect the impressions that males had of the females. Contrary to what was hypothesized, the results showed that the males were more likely to be attracted to perfumed females only when they were in the informal dress. When the perfumed females were dressed neatly, the males were less attracted to them. In another study, Baron (1983) conducted a 2 X 2 X 2 factorial design where he examined the following factors: perfume wearing (on vs. off) of interviewees, sex of the interviewees, and sex of the job interviewers (i.e., the subjects). He found that when an interviewee wore perfume, the scent increased his or her attractiveness only to female interviewers. However, male interviewers had an opposite reaction: they found the perfumed interviewees less attractive. In a related study, Baron (1986) conducted a 2 X 2 X 2 factorial design where he examined perfume wearing (on vs. off) of interviewees, the use of positive nonverbal cues (e.g., smiling and eye contact) by interviewees (used vs. not used), and sex of the job interviewers (i.e., the subjects). The two confederate interviewees in the study were females. The results showed that perfume wearing increased the attractiveness of the interviewee only for the male interviewer: the female interviewers showed equal amounts of attraction for the scented and unscented interviewees. From the above studies, one can see that the effects of perfume on social attraction are not straight forward. Whether a perfume will enhance the physical attraction of an individual depends on a variety of mitigating factors.

\section{Method}

\subsection{Treatment And Procedures}

An experienced young female interviewer was used to conduct personal interviews at an indoor mall in Burbank, California during two consecutive Friday-Saturday periods in the fall of 2002. During each interviewing session, she positioned herself near the mall escalator so that she could intercept people either before they entered or after they exited the escalator. On each Friday-Saturday period, she interviewed during the same hours, dressed the same (black pants, a white blouse, and a burgundy vest), and used the same introductory script. The only item that she varied during the two Friday-Saturday periods was the use of perfume. She interviewed without perfume during the first Friday-Saturday and with it on the following Friday-Saturday. To apply the perfume, the interviewer used three sprays - one on each side of the neck and one on the back of the neck.

The perfume used in the experiment is called "Love Spell," a floral scented item distributed by Victoria's Secret. The floral scent has been shown in previous studies to have a positive effect on mood (e.g., Baron and Thomley 1994), and it was an appropriate scent for a female interviewer. A pretest of the scent revealed that it could be detected when an individual came within three feet of the interviewer. 


\subsection{Dependent Measures}

The questionnaire used in this study inquired about the subject's use of, and attitude towards, modern and alternative medicines. It was a 57 item instrument that took up to 15 minutes to administer. Each of the dependent variables analyzed in this study is defined below.

Response rate is defined as the number of usable questionnaires administered divided by the number of interviews attempted. A questionnaire was considered usable only if it was at least $75 \%$ complete.

Item omission rate is defined as the number of questionnaire items left unanswered. This variable is based upon the 53 items that all respondents should have answered.

Sample bias was measured by comparing the control and treatment groups on four demographic variables (sex, age, education, and income) and on three pertinent survey items. Sample bias was measured to determine if the treatment (i.e., perfume) had any tendency to appeal to a specific demographic or attitudinal group.

\section{Results}

Eighty-eight personal interview attempts were made on the first Friday-Saturday period when no perfume was used, while seventy-six interview attempts were made during the following Friday-Saturday period when perfume was applied. The results provide support for our research hypothesis, for the interviewer received a significantly higher response rate when she was wearing perfume than when she was not $\left(47 \%\right.$ vs. $34 \%, \mathrm{X}^{2}(1)=$ $3.07, \mathrm{p}<.10)^{1}$ sample bias.

There were no significant differences between the treatment and control groups on item omission rate or

\section{Discussion}

This study's results suggest that perfume can be used to enhance the response rate to a face-to-face survey without incurring a sample bias or affecting the item omission rate. It appears that the potential interviewee noticed the perfume - at either a conscious or subliminal level - at that the scent facilitated approach behavior. Alternatively, it could be argued that the perfume affected mainly the interviewer and not the interviewee. That is, it is possible that the interviewer felt more attractive, sexy, and inviting while wearing perfume. Her enhanced feeling of attractiveness could have given her more confidence, enabling her to me more successful at completing an interview than when she was not wearing perfume.

Given that most controlled experimental investigations of the effects of scent report null effects rather than significant effects (Bone and Ellen 1999), we feel fortunate that our perfume treatment appeared to have a significant effect on the response rate. It will be interesting to see if our results can be duplicated in a future study. Future researchers should realize, however, that applying the perfume used in this study to a different interviewer could have different odor effects since each interviewer's body chemistry may react differently with the perfume.

Because of the nature of our research design, it is not conclusive that the perfume caused the increase in response rate during the period of the treatment. Other factors could explain why the second Friday-Saturday period (when the perfume was applied) experienced a higher response rate. First, there could be a problem with selection bias. That is, since potential interviewees were not randomly assigned to the experimental conditions, it is possible that those people encountered in the second interviewing period were simply more receptive towards interviewing than the first group. We see no reason why the second group would be more receptive, but this is a possibility. Second, there could be a problem with the interviewer learning from her mistakes during the first interviewing session and applying that information to her second interviewing period. Thus, she could have simply been better

\footnotetext{
1 With one degree of freedom, the $\mathrm{X}^{2}$ value tends to be overstated. This problem was dealt with by using the Yates correction for continuity
} when calculating the $\mathrm{X}^{2}$ value (Parsons 1974). 
during the second period at persuading people to be interviewed. Although this explanation has some merit, one should realize that the interviewer used in this study had two years of interviewing experience. She was used to interviewing in the mall where the study took place and she was equally comfortable approaching people during both interviewing periods. Given her interviewing background, it is unlikely that she could have learned enough during the first period to significantly increase her performance during the second period. Moreover, she made every attempt to remain consistent in her approach to people during both periods. Another plausible reason for the response rate being higher in the second interviewing period relates to expectancy effects (Rosenthal 1969). The interviewer was aware of the study's hypothesis and that knowledge could have caused her in subtle unknown ways to perform better during the period the treatment was applied. There is no way for us to know the extent, if at all, that expectancy effects occurred.

There are many challenges that researchers face when investigating the effects of scent on interviewer performance. First, one must find a scent that is pleasing and inviting to most people. Under ideal conditions, this scent should be pretested on the skin of the interviewer to determine if the resulting odor is attractive. Even if one finds a perfume that produces a pleasant odor on the skin, there is no guarantee that it will enhance the interviewing experience. Hirsch (1995) experimented with two pleasant ambient scents to determine their effects on gambling behavior. Though both scents were pleasant, only one of them increased the amount of money spent by gamblers. There is also the question of the amount of perfume that should be applied, i.e., the scent intensity. The interviewer should certainly wear enough perfume so that its fragrance is noticed, but s/he should not exceed an optimal point where the fragrance will become overpowering and noxious (Henion 1971). Unfortunately, the optimal strength of a perfume application will depend upon the scent sensitivity of the persons being interviewed, a factor that most likely will be unknown by the interviewer. It has been estimated that $10 \%$ of the population suffers reactions to fragrances (Sloan 1995), and these types of people would most likely be annoyed by an interviewer wearing any perfume.

Future researchers would be wise to use designs that randomly expose the potential interviewee to the scented or unscented interviewers. Moreover, the questionnaire used in a scent experiment could include items or scales that measure the respondent's alertness, mood, attraction for the interviewer, and awareness of scent. In addition, the interviewer could use a stopwatch to time the interview to see if the scent causes lingering behavior. It would also be illuminating to use a variety of male and female interviewers and to have each one note the sex of the potential interviewee. Armed with this information, a researcher could determine whether gender of the interviewer and interviewee affects the results of a scent treatment. Clearly, investigating the extent to which scent can enhance an interviewer's performance presents a challenging and fertile ground for future research.

\section{References}

1. Bainbridge, Jane (1998), "Scenting Opportunities," Marketing, Vol. 19 (Feb.), 36 - 37.

2. Benney, Mark, David Riesman, and Shirley A. Star (1956), "Age and Sex in the Interview," The American Journal of Sociology, Vol. 62 (Sept.), 143 - 152.

3. Baron, Robert A. (1981), "Olfaction and Human Social Behavior: Effects of a Pleasant Scent on Attraction and Social Perception," Personality and Social Psychology Bulletin, Vol. 7 (4), 617 - 620.

4. (1983), "Sweet Smell of Success," The Impact of Pleasant Artificial Scents on Evaluations of Job Applicants," Journal of Applied Psychology, Vol. 68 (4), 709 - 713.

5. (1986), "Self-Presentation in Job Interviews: When There Can Be 'Too Much of a Good Thing,," Journal of Applied Social Psychology, Vol. 16 (1), 16 - 28.

6. (1990), "Environmentally-Induced Positive Affect: its Impact on Self-Efficacy, Task Performance, Negotiation, and Conflict," Journal of Applied Social Psychology, Vol. 20, 368 - 384.

7. (1997), "The Sweet Smell of ... Helping: Effects of Pleasant Ambient Fragrance on Prosocial Behavior in Shopping Malls," Personality and Social Psychology Bulletin, Vol. 23 (5), 498 - 503.

8. and Jill Thomley (1994), "A Whiff of Reality: Positive Affect as a Potential Mediator of the Effects of Pleasant Fragrances on Task Performance and Helping," Environment and Behavior, Vol. 28 (6), 766 -784.

9. Bone, Paula F. and Pam S. Ellen (1994), "Olfaction and Marketing: Does it Make Sense to Use Scents?," unpublished working paper, Department of Marketing, West Virginia University. 
10. Collins, Martin (1980) "Interviewer Variability: A Review of the Problem," Journal of the Market Research Society, Vol. 22 (2), 77 - 95.

11. Colombotos, John, Jack Elinson, and Regina Loewenstein (1968), "Effect of Interviewers' Sex on Interview Responses," Health Reports, Vol. 83 (8), 685 - 690.

12. Chase, Victor D. (1998), "Making Stereophonic Scents," Appliance Manufacturer, Vol. 46 (1), 12.

13. Dunn, C., J. Sleep, and D. Collett (1995), "Sensing an Improvement: An Experimental Study to Evaluate the Use of Aromatherapy, Massage, and Periods of Rest in an Intensive Care Unit," Journal of Advanced Nursing, Vol. 21, 34 - 40.

14. Freeman, John and Edgar W. Butler (1976), "Some Sources of Interviewer Variance in Surveys," Public Opinion Quarterly, Vol. 40, 79 - 91.

15. Gueguen, Nicolas (2001), "Effect of a Perfume on Prosocial Behavior of Pedestrians," Psychological Reports, Vol. 88 (3), 1046 - 1048.

16. Henion, K. E. (1971), "Odor Pleasantness and Intensity: A Single Dimension," Journal of Experimental Psychology, Vol. 90 (2), 275 - 279.

17. Hirsch, Alan (1995), "Effects of Ambient Odors on Slot Machine Usage in a Las Vegas Casino," Psychological and Marketing, Vol. 12 (7), 585 - 594.

18. Hunter, Beatrice Trum (1995), "The Sales Appeal of Scents," Consumers' Research Magazine, Vol. 78 (Oct.), 8 - 9.

19. Goyder, John (1994), “An Experiment with Cash Incentives on a Personal Interview Survey," Journal of the Market Research Society, Vol. 36 (4), 360 - 366.

20. Huddy, Leonie, Joshua Billig, John Bracciodieta, Lois Hoeffler, Patrick J. Moynihan, and Patricia Pugllani (1997), "The Effect of Interviewer Gender on the Survey Response," Political Behavior, Vol. 19 (3), $197-220$.

21. Knasko, S. (1989), “Ambient Odor and Shopping Behavior,” Chemical Senses, Vol. 14, 718.

22. Lawless, H. T. (1991), "A Sequential Contrast Effect in Odor Perception," Bulletin of the Psychonomic Society, Vol. 29, 317 - 319.

23. Lorig Tyler S. and Gary E. Schwartz (1988), "Brain and Odor: I. Alteration of Human EEG by Odor Administration," Psychobiology, Vol. 16 (3), 281 - 284.

24. Lynn, Peter (2001), "The Impact of Incentives on Response Rates to Personal Interview Surveys: Role and Perceptions of Interviewers," International Journal of Public Opinion Research, Vol. 13 (3), 326 - 336.

25. Lynn, Peter, Patten Smith, and Rachel Turner (1998), "Assessing the Effects of an Advance Letter for a Personal Interview Survey," Journal of the Market Research Society, Vol. 40 (3), 265 - 272.

26. Mattila, Anna S. and Jochen Wirtz (2001), "Congruency of Scent and Music as a Driver of In-Store Evaluations and Behavior," Journal of Retailing, Vol. 77, 273-289.

27. Mehrabian, Albert and James A. Russell (1974), An Approach to Environmental Psychology, Cambridge, MA: The MIT Press.

28. Morrin, Maureen and S. Ratneshwar (2000), "The Impact of Ambient Scent on Evaluation, Attention, and Memory for Familiar and Unfamiliar Brands," Journal of Business Research, Vol. 49 (2), 157-165.

29. (2003), "Does it Make Sense to Use Scents to Enhance Brand Memory?" Journal of Marketing Research, Vol. XL (February), $10-25$.

30. Neff, Jack (2000), "Product Scents Hide Absence of True Innovation," Advertising Age, Vol. 7 (Feb. 21), 22.

31. Parsons, Robert (1974), Statistical Analysis: A Decision-Making Approach, New York: Harper \& Row.

32. Petran, Meredith (1998), "Bakes Great, Less Filling," Restaurants \& Institutions, Vol. 108 (8), 100.

33. Reda, Susan (1994), "Dollars and Scents," Stores, Vol. 76 (Aug.), 38-39.

34. Rosenthal, Robert (1969), "Interpersonal Expectations: Effects of the Experimenter's Hypothesis," in Robert Rosenthal and Ralph L. Rosnow (Eds.), Artifact in Behavioral Research (181 - 277), New York: Academic Press.

35. Schwartz, Gary E., D. Whitehorn, J. C. Hernon, and M. Jones (1986a), "The ARC Method for Averaging Repetitive Cycles: Application to Respiration During Stress and Relaxation,” Psychophysiology, Vol. 23 (4), 460

36. Schwartz, Gary E., D. Whitehorn, J. C. Hernon, and M. Jones (1986b), "Subjective and Respiratory Differences of Fragrances: Interaction with Hedonies," Psychophysiology, Vol. 23 (4), 460. 
37. Singer, Eleanor, Nancy Gebler, Trivellore Raghunathan, John Van Hoewyk, and Katherine McGonagle (1999), "The Effects of Incentives in Interviewer-Mediated Surveys," Journal of Official Statistics, Vol. 15, $217-230$.

38. Shmuel, Ellis and Jacob Hornick (1989), "Strategies to Secure Compliance for a Mall Intercept Interview," Public Opinion Quarterly, Vol. 52 (4), 539 - 551.

39. Sloan, Pat (1995), "Smelling Trouble," Advertising Age, Vol. 66 (Sept. 11), 1+.

40. Spangenberg, Eric R., Crowley, Any E., and Pamela W. Henderson (1996), "Improving the Store Environment: Do Olfactory Cues Affect Evaluations and Behaviors?, Journal of Marketing, Vol. 60 (2), $67-80$.

41. Takagi, Sadayuki F. (1989), Human Olfaction, Tokyo: University of Tokyo Press.

42. Webster, Cynthia (1996), "Hispanic and Anglo Interviewer and Respondent Ethnicity and Gender: The Impact on Survey Response Quality," Journal of Marketing Research, (Feb.), 62 - 72.

43. Wilkie, Maxine (1995), "Scent of a Market," American Demographics, Vol. 17 (Aug.), 40 - 49.

44. Willimack, Diane K., Howard Schuman, Beth-Ellen Pennell, James M. Lepkowski (1995), "Effects of a Prepaid Nonmonetary Incentive on Response Rates and Response Quality in a Face-to-Face Survey," Public Opinion Quarterly, Vol. 59, 78 - 92.

Notes 
Notes 